\title{
ATF3 transcription factor and its emerging roles in immunity and cancer
}

\author{
Matthew Thompson, Dakang Xu, and Bryan R.G. Williams* \\ Monash Institute of Medical Research, Monash University, Melbourne, Australia
}

\begin{abstract}
Activating transcription factor 3 (ATF3) is a member of the ATF/cyclic AMP response elementbinding (ATF/CREB) family of transcription factors. It is an adaptive-response gene that participates in cellular processes to adapt to extra- and/or intracellular changes, where it transduces signals from various receptors to activate or repress gene expression. Advances made in understanding the immunobiology of Toll-like receptors have recently generated new momentum for the study of ATF3 in immunity. Moreover, the role of ATF3 in the regulation of the cell cycle and apoptosis has important implications for understanding susceptibility to and progression of several cancers.
\end{abstract}

\section{Keywords}

ATF3; Transcriptional regulation; Immunity; TLRs; Oncogenesis

\section{Introduction}

The activating transcription factor (ATF) family represents a large group of basic-region leucine zipper (bZIP) transcription factors. ATF/cyclic AMP response element-binding (CREB) family members include ATF1 (also known as TREB36), CREB, CREM, ATF2 (also known as CRE-BP1), ATF3, ATF4, ATF5 (also known as ATFX) ATF6, ATF7, and B-ATF [1]. The common feature that these proteins share is the bZIP element. The basic region in this domain is responsible for specific DNA binding, while the leucine zipper region is responsible for forming homodimers, or heterodimers with other bZIP containing proteins such as the AP-1, C/EBP or Maf families of proteins [1]. ATF/CREB proteins were initially identified for their binding to the cyclic AMP response element (CRE) in various promoters, which has the consensus sequence TGACGTCA [2,3].

Cloning of the ATF3 full-length cDNA revealed a deduced protein sequence of 181 amino acids with a calculated molecular mass of $22 \mathrm{kD}$. [4,5]. An alternatively spliced form of ATF3 cDNA which encoded a truncated isoform (ATF3 $\Delta$ Zip) that lacked the leucine zipper dimerisation domain was also identified. The longer isoform of ATF3 was initially suggested to homodimerise and repress rather than activate transcription of promoters with ATF binding elements. However, ATF3 has been shown to dimerise with other ATF/CREB proteins, including ATF2 [4], c-Jun [6-8], Jun B [7,8] and JunD [9-11]. Depending on the promoter context, these heterodimers can act as either repressors or activators of transcription [12]. Therefore, the role of ATF3 as a repressor or activator of transcription cannot be generalised. This is especially true in vivo, where the presence or absence of other ATF/CREB family members may ultimately decide the role of ATF3 in transcriptional 
regulation. ATF3 $\triangle$ Zip does not bind DNA, yet it is able to stimulate transcription, possibly by preventing the access of inhibitory co-factors to gene promoters [5]. Therefore, it is possible that alternative splicing of the ATF3 gene may be physiologically important in the regulation of target genes.

ATF3 expression is maintained at low levels in quiescent cells. Extensive studies have characterised ATF3 as an adaptive response gene $[1,13]$ that is induced by a wide variety of signals including those initiated by cytokines, genotoxic agents or physiological stresses [1]. Interestingly, unlike other ATF family members, emerging evidence has implicated ATF3 in host defence against invading pathogens and cancer. These processes are controlled by the efficient coordination of cell responses and genetic regulatory networks which allow this key transcription factor to modulate the expression of a diverse set of target genes, depending on the cell type and/or the nature of the stimuli. Therefore the purpose of this review will be to highlight the recent discoveries regarding ATF3 regulation of immunity in addition to its contradictory roles in oncogenesis.

\section{Regulation of innate immune responses}

The innate immune system detects the presence of pathogens or tumours through a variety of different mechanisms, involving both cell surface receptors and intracellular sensors. Prominent among these pathogen sensors is the Toll-like receptor (TLR) family. To date, 10 and 13 TLR genes have been cloned in human and mouse respectively; with each of the TLRs appearing to recognise a unique set of pathogen-associated molecular patterns (PAMPs) [14]. TLR1, 2, 4, 5 and 6 are expressed on the cell surface membrane and recognise bacterial and fungal products, while TLR3, 7, 8 and 9 reside in intracellular endosomes and specialise in detection of pathogen-associated nucleic acids. Following recognition of their ligands, TLRs trigger intricate cellular signalling pathways that endow cells with antiviral and antibacterial states and promote the expression of inflammatory cytokines, chemokines and co-stimulatory molecules that are critical for the activation of adaptive immune responses. In addition, TLR signalling has been implicated as a regulator of tumour development $[15,16]$. Here, we summarise the recent discoveries regarding the role of ATF3 regulation in immunity, particularly with respect to the TLR signalling pathways.

\section{Identifying the role of ATF3 in immune regulation}

A role for ATF3 in immune regulation was initially identified following a series of experiments investigating the mechanisms involved in the ability of an alphavirus-based DNA vaccine to mediate rejection of $\mathrm{B} 16-\mathrm{F}_{10}$ melanomas. The alphavirus vector, encoding melanoma antigen, was shown to also produce immunostimulatory PAMPs including CpGDNA and double-stranded RNA (dsRNA) [17-19]. Subsequent co-administration of immunostimulatory dsRNA (synthetic mimetic poly:IC (pIC)) and CpG-containing oligodeoxynucleotides (CpG-ODN), in the absence of melanoma antigen, exhibited synergistic activity against B16- $\mathrm{F}_{10}$ melanoma in C57BL6 mice, via the activation of TLR signalling [20]. Later microarray transcript profiling of murine bone marrow macrophages (BMM) treated simultaneously with pIC and CpG-ODN identified atf 3 as a key transcript up-regulated synergistically by the combined signalling of TLR3 and TLR9 [21].

\section{ATF3 as a negative regulator of immune function}

Consistently, treatment of BMMs with lipopolysaccharide (LPS) (TLR4), pIC (TLR3), CpG-ODN (TLR9), pIC/CpG-ODN (TLR3 and TLR9) and zymosan (TLR2/6 heterodimer) was shown to significantly elevate ATF3 protein expression, demonstrating that ATF3 induction occurs in response to a wide range of TLRs [21]. This identified ATF3 as a 
potential transcriptional regulator of TLR signalling in macrophages. Accordingly, atf3 deficient primary macrophages produced elevated amounts of IL-6 and IL-12p40 cytokines in response to a range of activated TLRs, and elevated TNF- $\alpha$ production following TLR9 activation alone [21]. This confirmed and extended an earlier study that demonstrated ATF3 induction following TLR4 stimulation, and increased IL- 6 and IL-12b production in atf 3 deficient BMMs treated with LPS [22]. Therefore, ATF3 is able to negatively regulate transcription of pro-inflammatory cytokines. Interestingly, these are genes that possess ATF/ CREB promoter binding sites within close proximity of NF- $\mathrm{kB}$ sites [22], suggesting that ATF3 may modulate NF- $\kappa$ B related transcription. Accordingly, the association of ATF3 with histone deacetylase 1 (HDAC1), may be the possible mechanism that antagonises transcription of NF- $\mathrm{\kappa B}$ target genes [22]. Negative regulation by ATF3 may also occur indirectly. For example, ATF3 can negatively regulate IL-6 transcription by inhibiting expression of CEBP $\delta$, which is a positive regulator of IL-6 [23]. These data suggest that ATF3 functions in a negative feed-back loop response to suppress TLR mediated cytokine expression. This implicates ATF3 as a key regulator of immunity against invading pathogens and inflammatory diseases.

\section{The role of ATF3 in inflammatory diseases}

The atf 3 knockout mouse has proved a useful tool in further dissecting the role of ATF3 in immune regulation [24]. In accord with its role as an inducible adaptive response gene, atf3 knockouts exhibit no developmental abnormalities, with phenotypes only appearing when the mice are challenged with stress stimuli. Consistent with evidence that ATF3 negatively regulates pro-inflammatory cytokine production, atf 3 deficient mice administered LPS intraperitoneally have significantly elevated serum IL- 6 and IL-12b levels compared to wild type controls, in line with in vitro data [22]. Furthermore, the atf 3 deficient mice displayed an overt susceptibility to endotoxic shock induced death, with all individuals succumbing within 24 hours of exposure, compared to wild types which survived until at least 36 hours post injection. These data suggest that negative feedback regulation by ATF3 is critical for the prevention of acute inflammatory syndromes by limiting pro-inflammatory cytokine expression in response to pathogen related signals. Consistent with the harmful affects of increased cytokine production, PR8 influenza infected atf3 deficient mice experienced delayed weight recovery following resolution of the infection [21]. Cytotoxicity associated with elevated TNF- $\alpha$ levels may be responsible for this observation, as increased levels of this cytokine were expressed in the spleens of atf 3 null mice treated intra-peritoneally with a TLR9 PAMP, CpG-ODN. Though the proportions of circulating PR8 influenza specific neutralising antibodies or $\mathrm{CD}^{+} \mathrm{T}$ cells were not significantly altered in knockout mice infected with the virus, it could not be ruled out that clearance of the virus was inhibited. In a mouse model of ovalbumin allergen induced asthma, ATF3 expression was shown to be significantly increased [25]. When compared to wild type, atf3 null mice exhibited significantly increased airway resistance, which corresponded with increased inflammatory cell infiltrate, including macrophages, lymphocytes and eosinophils as assessed by brochoalveolar lavage (BAL). Activated $\mathrm{CD}^{+} \mathrm{T}$ lymphocytes from atf 3 deficient mice expressed elevated IL-4, IL-5 and IL-13. ATF3 was shown to bind the IL-4, IL-5 and IL-13 promoters, and antagonise transcription mediated by JunB, an AP-1 family member. Additionally, the chemokines CCL2, 7, 8, 11 and CXCL1, 2, 5 were highly expressed in atf3 deficient lungs, suggesting that ATF3 negatively regulates their transcription. ATF3 has also been implicated in the transcriptional regulation of a related chemokine, CCL4, in murine macrophages, supporting a role for ATF3 regulation of inflammatory chemokines, and not only cytokines [26]. From these data it is clear that ATF3 has important roles in the suppression of inflammatory responses to infection and allergy. Likewise, atf 3 deficiency in these animal models of inflammation appears to be systematically harmful because of increased cytokine production and increased inflammatory cell infiltrate associated with 
increased chemokine output. In contrast to these data, atf 3 deficiency has been demonstrated to be beneficial in the clearance of murine cytomegalovirus (MCMV) infection. atf3 deficient mice injected with a sublethal dose of MCMV possessed significantly reduced titres and pathology in livers, after 3 days, compared to wild type [27]. Furthermore, common $\gamma$-chain ${ }^{-/-} \mathrm{Rag}^{-{ }^{-/}}$mice, lacking natural killer (NK) cells and T lymphocytes, reconstituted with atf 3 deficient NK cells displayed significantly reduced MCMV titres in the liver, 48 hours post infection, demonstrating that ATF3 acts directly in NK cells. In this regard, ATF3 was shown to be induced after activation of NK cells by IL-12 and anti-CD28 antibody. The improved function of atf 3 deficient NK cells was attributed to increased expression of IFN- $\gamma$, a potent regulator of NK cell activity. Overall, these data demonstrate that ATF3 is required for the maintainance of normal host defence mechanisms (Figure 1, Table 1). This raises the possibility that ATF3 could be targeted and induced therapeutically to help combat excessive inflammatory responses, or conversely ATF3 could be silenced in order to bolster inadequate immune defence.

\section{Regulation of oncogenesis}

Emerging evidence suggests that ATF3 may play another critical function in host defence by regulating the delicate balance between proliferative and apoptotic signals that contribute to the development of cancer. Interestingly, ATF3 has been demonstrated to play differing roles in cancer development depending on the cell type and context. This fact is perhaps best exemplified by the recently reported dichotomous role of ATF3 in syngeneic breast cancer cell lines. ATF3 overexpression protected malignant MCF10CA1a human breast cancer cells from apoptosis and promoted their metastatic potential, associated with an upregulation of fibronectin-1, TWIST1 and Slug transcripts [28]; which are key regulators of cell-cell or cell-extracellular matrix interaction. Conversely, ATF3 was shown to enhance apoptosis in the untransformed MCF10A mammary epithelial cell line. Accordingly, we summarise the controversial roles of ATF3 in both oncogenesis and tumour suppression.

\section{ATF3 as an oncogene}

There are many studies that support an oncogenic role of ATF3. Most striking are studies that have demonstrated correlative evidence of ATF3 overexpression in human cancer tissue. For example, ATF3 expression was found to be elevated in a significant number of human breast cancers, potentially due to amplification of the ATF3 gene localised within the chromosome 1q amplicon, a region that is the most frequently amplified region in breast tumours [28]. Similarly, ATF3 is highly expressed in malignant human prostate cancer tissue, with the highest expression patterns observed in tumours possessing poorer prognostic indicators [29]. High expression of ATF3 has also been observed in Hodgkin compared to non-Hodgkin lymphomas and non-malignant tissue [30]. These studies therefore provide correlative evidence which suggests that ATF3 expression contributes to the successful propagation of human cancer.

Consistent with these findings, loss- and gain-of-function approaches suggest that ATF3 may be oncogenic as it can be protective against apoptosis and in many cases can also promote metastasis of cell lines in vitro and in vivo. Overexpression of ATF3 in Du-145 human prostate cancer cells resulted in increased proliferation and G1-to-S growth phase transition [29]. In another model of prostate cancer, atf3 transcription was shown to be inhibited by Drg-1, a suppressor of metastasis [31]. This suggested that ATF3 functions to promote metastasis in prostate cancer. In line with this, overexpression of ATF3 promoted motility and invasiveness of human PC-3MM and ALVA prostate cancer cells, whilst also promoting lung metastasis of rat AT2.1 prostate cancer cells injected subcutaneously into SCID mice. ATF3 was similarly suggested to contribute to metastasis, as cell adhesion and cell invasion were inhibited by expression of anti-sense ATF3 oligonucleotides in HT29 
human colon cancer cells [32]. Furthermore, anti-sense ATF3 decreased growth of HT29 cell xenografts, correlating with increased survival of affected mice. Loss of ATF3 function, by small interfering RNA knockdown, has also been shown to reduce proliferation and viability of L428 and L540Cy Hodgkin lymphoma cells [30]. These data suggest that ATF3 expression has the potential to promote cancer progression. However the mechanisms and transcriptional targets, through which ATF3 can allow cancer cells to remain viable, proliferate and eventually spread, are still largely undefined. GADD153 represents one known target gene which may allow ATF3 to promote oncogenesis. GADD153 expression is known to induce cell cycle arrest and apoptosis in response to cellular stress factors $[33,34]$ and is also known to promote apoptosis of cancer cell lines in response to antitumourigenic compounds $[35,36]$. Importantly, overexpression studies demonstrated that ATF3 could bind the GADD153 promoter and repress its transcription in HeLa cells [37], providing a possible avenue through which ATF3 could promote survival of cancer cells.

\section{ATF3 in tumour suppression}

In contrast to the studies above, some evidence suggests that ATF3 may be able to inhibit tumourigenesis. Firstly, ATF3 appears to be expressed at lower levels in human colorectal cancer [38], suggesting that loss of ATF3 function results in loss of tumour suppression. This is in line with studies that have suggested that ATF3 may be able to promote apoptosis and reduce the metastatic potential in varied cell lines, in order to prevent cancer development. For example, ATF3 overexpression results in increased apoptosis of PC3 human prostate cancer cells [39]; reduced focus formation and reduced size of subcutaneous HCT-116 human colorectal cancer cell xenografts in nude mice [40]; increased apoptosis and metastatic potential of human ovarian cancer cells [41]. The potential role of ATF3 as a tumour suppressor is also supported by its defined role in transforming growth factor beta (TGF $\beta$ ) signalling [42]. TGF $\beta$ is a potent tumour suppressor in epithelial cells, which signals via Smad3 activation to directly induce ATF3. ATF3 and Smad3 then form a complex that directly mediates $I d I$ repression through binding its promoter. Id 1 is able to induce cancer cell growth and promote cell survival and has been demonstrated to be overexpressed in many different cancer types [43], indicating a possible mechanism through which ATF3 can suppress tumourigenesis. In addition, ATF3 can also be induced by a range of antitumourigenic compounds, including curcumin [44], non-steroidal anti-inflammatory drugs [38], progesterone [41] and the phosphatidylinositol inhibitor LY294002 [45]. If ATF3 does indeed act as a tumour suppressor, it may be responsible in part for the action of these compounds. However, induction of ATF3 by treatment with these compounds may result in deleterious effects if ATF3 functions as an oncogene [28].

\section{Mouse models in understanding the action of ATF3 in oncogenesis}

Transgenic mouse models have also proved useful tools to delineate the possible function of ATF3 in cancer. Mice overexpressing ATF3 in basal epithelial cells under the control of the bovine cytokeratine 5 promoter (BK5.ATF3), possessed epidermal hyperplasia, hair follicle anomalies and incidences of oral squamous cell carcinoma and basal cell tumours at 16 months of age [46]. Similarly, biparous BK5.ATF3 mice developed mammary carcinomas between 6 and 12 months of age [47]. These studies suggest that ATF3 plays the role of an oncogene. Conversely, other studies have implicated ATF3 as a tumour suppressor, due to its ability to induce apoptosis and cell cycle arrest. atf 3 deficient primary pancreatic islets were partially protected from IL- $1 \beta / \mathrm{IFN}-\gamma$ or nitric oxide induced apoptosis [24]. This correlated with development of abnormal pancreatic islets and defects associated with $\beta$-cell deficiency in transgenic mice overexpressing ATF3 under the control of the PDX-1 promoter, likely indicating that these islets possessed apoptotic defects [24]. Islets isolated from transgenic mice expressing ATF3 in pancreatic $\beta$-cells under the control of the rat insulin promoter were later shown to exhibit higher rates of apoptosis, due to the ability of 
ATF3 to repress transcription of insulin receptor substrate 2 (IRS2) [48]. IRS2 disruption has been implicated in diabetes [49], but more importantly, IRS2 is a signalling adaptor molecule that promotes tumourigenesis and metastasis when transgenically expressed in murine mammary glands [50], identifying a possible mechanism through which ATF3 can suppress tumour development. Finally, in a loss-of-function approach, atf 3 deficient mouse embryonic fibroblasts (MEFs) were shown to transition from G1 to S phase growth more efficiently, compared to wild type [13]. atf 3 deficient fibroblasts were also more susceptible to transformation by oncogenic Ras, which correlated with increased size of xenograft tumours in nude mice, and higher growth rate of the cells in vitro [13]. Importantly, ATF3 was shown to bind the cyclin D1 promoter and repress its transcription. Cyclin D1 is an important regulator of $\mathrm{G} 1$ to $\mathrm{S}$ phase progression which has been implicated in the development and progression of many human cancers [51]. These data therefore support a role for ATF3 as a tumour suppressor via its ability to promote cell death and suppress cell cycle progression. Overall, however, ATF3 can not be clearly defined as an oncogene or tumour suppressor (Figure 1, Table 1).

\section{Conclusions and perspectives}

Host defence plays two major roles in the regulation of inflammatory responses and cancer. These processes require strict co-ordination of cellular responses to adapt to and control disease outcomes. ATF3 is an adaptive-response gene that participates in cellular processes to adapt to extra- and/or intracellular changes, where it transduces signals from various receptors to activate or repress gene expression. Accordingly, ATF3 can be implicated as a regulator of host defence mechanisms.

ATF3 is required to strictly regulate and limit key aspects of immune function, particularly to prevent immune pathologies associated with uncontrolled pro-inflammatory cytokine production. In support of this, current evidence largely indicates that atf 3 deficiency is detrimental to inflammatory disease conditions, including septic shock and asthma. Conversely, ATF3 deficiency has been shown to be beneficial for the clearance of MCMV infection. ATF3 induction could therefore prove a useful therapeutic strategy to reduce the harmful effects of unregulated immune responses, whereas ATF3 knockdown may be useful where immune responses are inadequate. Further studies should be conducted to firmly identify a role for ATF3 in cancer development. It is obvious that the cellular context strongly influences the roles of ATF3, so it is therefore important to identify ATF3 transcriptional targets and interacting partners in order to accurately gauge the contribution of ATF3 to cancer.

Clearly, ATF3 does not function in these processes alone and is known to directly and indirectly cooperate with or antagonise members of its own family, as well as members of other classes of transcription factors (Figure 1, Table 1). The relationship between ATF3 and NF- $\kappa \mathrm{B}$ is of particular interest because both are activated by a remarkably common set of stimuli, such as PAMPs and DNA damage. Furthermore, both transcription factors play essential roles in immune cell function. In this regard, however, ATF3 and NF- $\mathrm{KB}$ appear to exert opposite effects on the expression of many cytokines. Both have also been shown to regulate cell growth and survival. NF- $\mathrm{KB}$ acts as a potent pro-survival transcription factor and contributes to the development of tumours, including inflammation-linked cancers. Precisely how these two transcription factor families cooperate and antagonise one another is an important question to be addressed.

Given that ATF3 is critical for two aspects of host defence - immunity against pathogens and the progression of cancer - a more detailed understanding of how ATF3 regulates immune and oncogenic signalling pathways could make ATF3 an attractive target not only 
for therapy for infectious diseases and immune disorders, but also in the multidisciplinary therapy of cancers.

\section{Acknowledgments}

This work was supported in part by a grant from the National Institutes of Health (P01 CA062220). MT was supported by a scholarship from the Australian Rotary Health Research Fund / Rotary District 9650 Bowelscan.

\section{References}

1. Hai, T. The ATF transcription factors in cellular adaptive responses. In: Ma, J., editor. Gene Expression and Regulation. Higher Education Press; Beijing, China: Springer; New York, USA: 2006. p. 322-333.

2. Montminy MR, Bilezikjian LM. Binding of a nuclear protein to the cyclic-AMP response element of the somatostatin gene. Nature. 1987; 328:175-178. [PubMed: 2885756]

3. Deutsch PJ, Hoeffler JP, Jameson JL, Lin JC, Habener JF. Structural determinants for transcriptional activation by cAMP-responsive DNA elements. J Biol Chem. 1988; 263:18466-18472. [PubMed: 2848037]

4. Hai T, Liu F, Coukos WJ, Green MR. Transcription factor ATF cDNA clones: an extensive family of leucine zipper proteins able to selectively form DNA-binding heterodimers. Genes Dev. 1989; 3:2083-2090. [PubMed: 2516827]

5. Chen BP, Liang G, Whelan J, Hai T. ATF3 and ATF3 $\triangle$ Zip: transcriptional repression versus activation by alternatively spliced isoforms. J Biol Chem. 1994; 269:15819-15826. [PubMed: 7515060]

6. Hai T, Curran T. Cross-family dimerization of transcription factors Fos/Jun and ATF/CREB alters DNA binding specificity. Proc Natl Acad Sci USA. 1991; 88:3720-3724. [PubMed: 1827203]

7. Hsu JC, Laz T, Mohn KL, Taub R. Identification of LRF-1, a leucine-zipper protein that is rapidly and highly induced in regenerating liver. Proc Natl Acad Sci U S A. 1991; 88:3511-3515. [PubMed: 1902565]

8. Hsu JC, Bravo R, Taub R. Interactions among LRF-1, JunB, c-Jun, and c-Fos define a regulatory program in the G1 phase of liver regeneration. Mol Cell Biol. 1992; 12:4654-6465. [PubMed: 1406655]

9. Chu HM, Tan Y, Kobierski LA, Balsam LB, Comb MJ. Activating transcription factor-3 stimulates 3',5'-cyclic adenosine monophosphate-dependent gene expression. Mol Endocrinol. 1994; 8:59-68. [PubMed: 8152431]

10. Fawcett TW, Martindale JL, Guyton KZ, Hai T, Holbrook NJ. Complexes containing activating transcription factor (ATF)/cAMP-responsive-element-binding protein (CREB) interact with the CCAAT/enhancer-binding protein (C/EBP)-ATF composite site to regulate Gadd153 expression during the stress response. Biochem J. 1999; 339(Pt 1):135-141. [PubMed: 10085237]

11. Nilsson M, Toftgard R, Bohm S. Activated Ha-Ras but not TPA induces transcription through binding sites for activating transcription factor 3/Jun and a novel nuclear factor. J Biol Chem. 1995; 270:12210-12218. [PubMed: 7744871]

12. Hai T, Wolfgang CD, Marsee DK, Allen AE, Sivaprasad U. ATF3 and stress responses. Gene Expr. 1999; 7:321-335. [PubMed: 10440233]

13. Lu D, Wolfgang CD, Hai T. Activating transcription factor 3, a stress-inducible gene, suppresses Ras-stimulated tumorigenesis. J Biol Chem. 2006; 281:10473-10481. [PubMed: 16469745]

14. Kawai T, Akira S. TLR signaling. Cell Death Differ. 2006; 13:816-825. [PubMed: 16410796]

15. Swann JB, Vesely MD, Silva A, Sharkey J, Akira S, Schreiber RD, Smyth MJ. Demonstration of inflammation-induced cancer and cancer immunoediting during primary tumorigenesis. Proc Natl Acad Sci U S A. 2008; 105:652-656. [PubMed: 18178624]

16. Rakoff-Nahoum S, Medzhitov R. Regulation of spontaneous intestinal tumorigenesis through the adaptor protein MyD88. Science. 2007; 317:124-127. [PubMed: 17615359] 
17. Leitner WW, Hwang LN, DeVeer MJ, Zhou A, Silverman RH, Williams BRG, Dubensky TW, Ying H, Restifo NP. Alphavirus-based DNA vaccine breaks immunological tolerance by activating innate antiviral pathways. Nature Medicine. 2003; 9:33-39.

18. Scheule RK. The role of CpG motifs in immunostimulation and gene therapy. Adv Drug Deliv Rev. 2000; 44:119-134. [PubMed: 11072110]

19. McCluskie MJ, Weeratna RD, Davis HL. The role of CpG in DNA vaccines. Springer Semin Immunopathol. 2000; 22:125-132. [PubMed: 10944807]

20. Whitmore MM, DeVeer MJ, Edling A, Oates RK, Simons B, Lindner D, Williams BRG. Synergistic activation of innate immunity by double-stranded RNA and CpG DNA promotes enhanced antitumour activity. Cancer Res. 2004; 64:5850-5860. [PubMed: 15313929]

21. Whitmore MM, Iparraguirre A, Kubelka L, Weninger W, Hai T, Williams BRG. Negative regulation of TLR-signaling pathways by activating transcription factor-3. J Immunol. 2007; 179:3622-3630. [PubMed: 17785797]

22. Gilchrist M, Thorsson V, Li B, Rust AG, Korb M, Kennedy K, Hai T, Bolouri H, Aderem A. Systems biology approaches identify ATF3 as a negative regulator of Toll-like receptor 4. Nature. 2006; 441:173-178. [PubMed: 16688168]

23. Litvak V, Ramsey SA, Rust AG, Zak DE, Kennedy K, Lampano AE, Nykter M, Shmulevich I, Aderem A. Function of C/EBP $\delta$ in a regulatory circuit that discriminates between transient and persistent TLR4-induced signals. Nat Immunol. 2009; 10:437-443. [PubMed: 19270711]

24. Hartman MG, Lu D, Kim ML, Kociba GJ, Shukri T, Buteau J, Wang X, Frankel WL, Guttridge D, Prentki M, Grey ST, Ron D, Hai T. Role for activating transcription factor 3 in stress-induced beta-cell apoptosis. Mol Cell Biol. 2004; 24:5721-5732. [PubMed: 15199129]

25. Gilchrist M, Henderson WR Jr, Clark AE, Simmons RM, Ye X, Smith KD, Aderem A. Activating transcription factor 3 is a negative regulator of allergic pulmonary inflammation. J Exp Med. 2008; 205:2349-2357. [PubMed: 18794337]

26. Khuu CH, Barrozo RB, Hai T, Weinstein SL. Activating transcription factor 3 (ATF3) represses the expression of CCL4 in murine macrophages. Mol Immunol. 2007; 44:1598-1605. [PubMed: 16982098]

27. Rosenberger CM, Clark AE, Treuting PM, Johnson CD, Aderem A. ATF3 regulates MCMV infection in mice by modulating IFN- $\gamma$ expression in natural killer cells. Proc Natl Acad Sci U S A. 2008; 105:2544-2549. [PubMed: 18268321]

28. Yin X, DeWille JW, Hai T. A potential dichotomous role of ATF3, an adaptive-response gene, in cancer development. Oncogene. 2008; 27:2118-2127. [PubMed: 17952119]

29. Pelzer AE, Bektic J, Haag P, Berger AP, Pycha A, Schäfer G, Rogatsch H, Horninger W, Bartsch $\mathrm{G}$, Klocker $\mathrm{H}$. The expression of transcription factor activating transcription factor 3 in the human prostate and its regulation by androgen in prostate cancer. J Urol. 2006; 175:1517-1522. [PubMed: 16516039]

30. Janz M, Hummel M, Truss M, Wollert-Wulf B, Mathas S, Jöhrens K, Hagemeier C, Bommert K, Stein H, Dörken D, Bargou RC. Classical Hodgkin lymphoma is characterized by high constitutive expression of activating transcription factor 3 (ATF3), which promotes viability of Hodgkin/ReedSternberg cells. Blood. 2006; 107:2536-2539. [PubMed: 16263788]

31. Bandyopadhyay S, Wang Y, Zhan R, Pai SK, Watabe M, Iiizumi M, Furuta E, Mohinta S, Liu W, Horita S, Hosobe S, Tsikada T, Miura K, Takano Y, Saito K, Commes T, Piquemal D, Hai T, Watabe K. The tumor metastatis suppressor gene Drg-1 down-regulates the expression of activating transcription factor 3 in prostate cancer. Cancer Res. 2006; 66:11983-11990. [PubMed: 17178897]

32. Ishiguro T, Nagawa H, Naito M, Tsuruo T. Inhibitory effect of ATF3 antisense oligonucleotide on ectopic growth of HT29 human colon cancer cells. Jpn J Cancer Res. 2000; 91:833-836. [PubMed: 10965025]

33. Zinszner H, Kuroda M, Wang X, Batchvarova N, Lightfoot RT, Remotti H, Stevens JL, Ron D. $\mathrm{CHOP}$ is implicated in programmed cell death in response to impaired function of the endoplasmic reticulum. Genes Dev. 1998; 12:982-995. [PubMed: 9531536] 
34. Maytin EV, Ubeda M, Lin JC, Habener JF. Stress-inducible transcription factor CHOP/gadd153 induces apoptosis in mammalian cells via p38 kinase-dependent and -independent mechanisms. Exp Cell Res. 2001; 267:193-204. [PubMed: 11426938]

35. Kim R, Ohi Y, Inoue H, Aogi K, Toge T. Introduction of gadd153 gene into gastric cancer cells can modulate sensitivity to anticancer agents in association with apoptosis. Anticancer Res. 1999; 19:1779-1783. [PubMed: 10470115]

36. Scott DW, Loo G. Curcumin-induced GADD153 gene up-regulation in human colon cancer cells. Carcinogenesis. 2004; 25:2155-2164. [PubMed: 15271854]

37. Wolfgang CD, Chen BP, Martindale JL, Holbrook NJ, Hai T. gadd153/Chop10, a potential target gene of the transcriptional repressor ATF3. Mol Cell Biol. 1997; 17:6700-6707. [PubMed: 9343434]

38. Bottone FG Jr, Martinez JM, Collins JB, Afshari CA, Eling TE. Gene modulation by the cyclooxygenase inhibitor, sulindac sulfide, in human colorectal carcinoma cells: possible link to apoptosis. J Biol Chem. 2003; 278:25790-25801. [PubMed: 12734198]

39. Huang X, Li X, Guo B. KLF6 induces apoptosis in prostate cancer cells through up-regulation of ATF3. J Biol Chem. 2008; 283:29795-29801. [PubMed: 18755691]

40. Bottone FG Jr, Moon Y, Kim JS, Alston-Mills B, Ishibashi M, Eling TE. The anti-invasive activity of cyclooxygenase inhibitors is regulated by the transcription factor ATF3 (activating transcription factor 3). Mol Cancer Ther. 2005; 4:693-703. [PubMed: 15897233]

41. Syed V, Mukherjee K, Lyons-Weiler J, Lau KM, Mashima T, Tsuruo T, Ho SM. Identification of ATF-3, caveolin-1, DLC-1, and NM23-H2 as putative antitumorigenic, progesterone-regulated genes for ovarian cancer cells by gene profiling. Oncogene. 2005; 24:1774-1787. [PubMed: 15674352]

42. Kang Y, Chen CR, Massague J. A self-enabling TGFbeta response coupled to stress signaling: Smad engages stress response factor ATF3 for Id1 repression in epithelial cells. Mol Cell. 2003; 11:915-926. [PubMed: 12718878]

43. Ling MT, Wang X, Zhang X, Wong YC. The multiple roles of Id-1 in cancer progression. Differentiation. 2006; 74:481-487. [PubMed: 17177845]

44. Yan C, Jamaluddin MS, Aggarwal B, Myers J, Boyd DD. Gene expression profiling identifies activating transcription factor 3 as a novel contributor to the proapoptotic effect of curcumin. Mol Cancer Ther. 2005; 4:233-241. [PubMed: 15713895]

45. Yamaguchi K, Lee SH, Kim JS, Wimalasena J, Kitajima S, Baek SJ. Activating transcription factor 3 and early growth response 1 are the novel targets of LY294002 in a phosphatidylinositol 3kinase-independent pathway. Cancer Res. 2006; 66:2376-2384. [PubMed: 16489044]

46. Wang A, Arantes S, Conti C, McArthur M, Aldaz CM, MacLeod MC. Epidermal hyperplasia and oral carcinoma in mice overexpressing the transcription factor ATF3 in basal epithelial cells. Mol Carcinog. 2007; 46:476-487. [PubMed: 17295236]

47. Wang A, Arantes S, Yan L, Kiguchi K, McArthur MJ, Sahin A, Thames HD, Aldaz CM, Macleod MC. The transcription factor ATF3 acts as an oncogene in mouse mammary tumorigenesis. BMC Cancer. 2008; 8:268. [PubMed: 18808719]

48. Li D, Yin X, Zmuda EJ, Wolford CC, Dong X, White MF, Hai T. The repression of IRS2 gene by ATF3, a stress-inducible gene, contributes to pancreatic beta-cell apoptosis. Diabetes. 2008; 57:635-644. [PubMed: 18057093]

49. Withers DJ, Gutierrez JS, Towery H, Burks DJ, Ren JM, Previs S, Zhang Y, Bernal D, Pons S, Shulman GI, Bonner-Weir S, White MF. Disruption of IRS-2 causes type 2 diabetes in mice. Nature. 1998; 391:900-904. [PubMed: 9495343]

50. Dearth RK, Cui X, Kim HJ, Hadsell DL, Lee AV. Oncogenic transformation by the signaling adaptor proteins insulin receptor substrate (IRS)-1 and IRS-2. Cell Cycle. 2007; 6:705-713. [PubMed: 17374994]

51. Knudsen KE, Diehl JA, Haiman CA, Knudsen ES. Cyclin D1: polymorphism, aberrant splicing and cancer risk. Oncogene. 2006; 25:1620-1628. [PubMed: 16550162] 


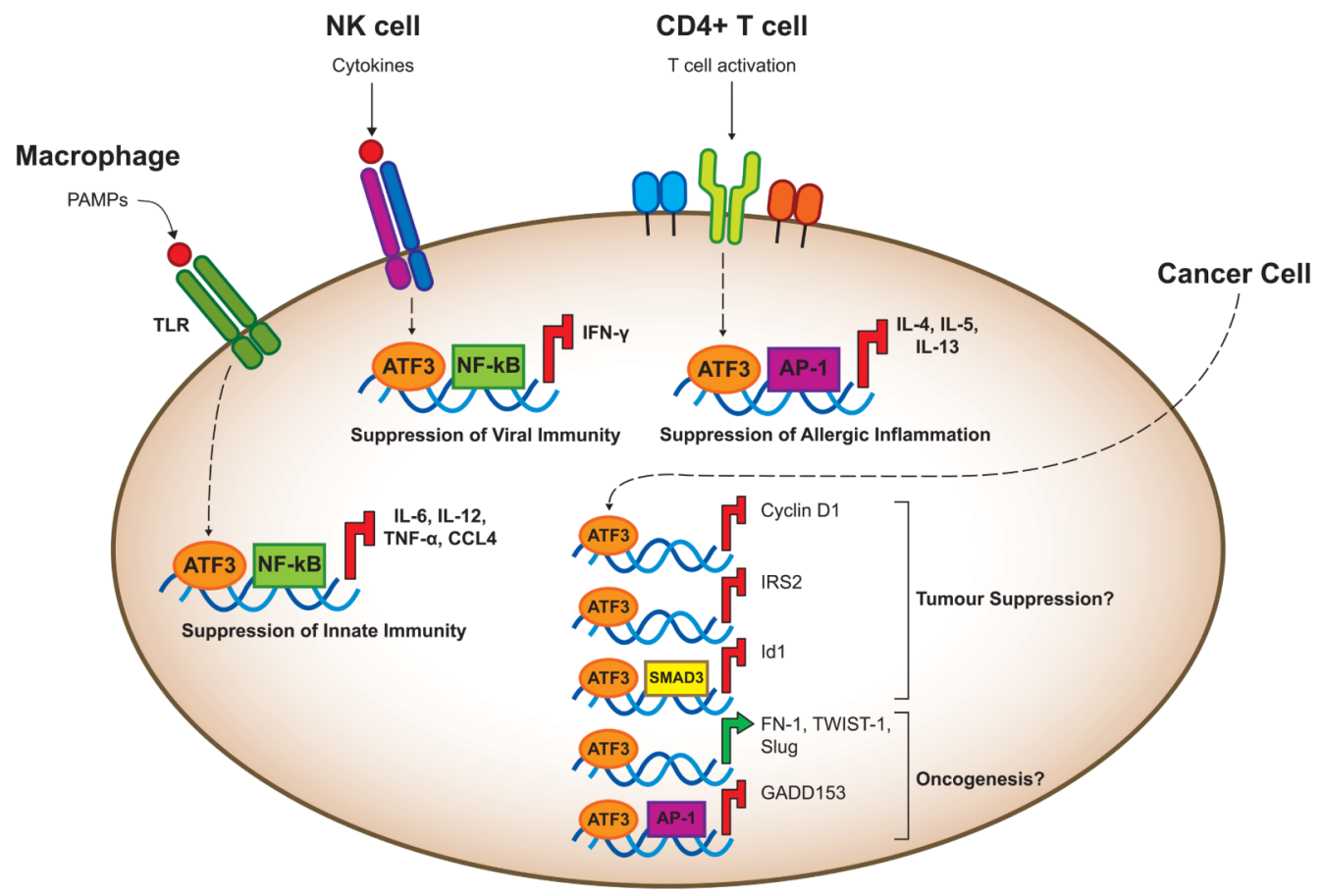

Fig. 1.

The role of ATF3 in host defence via the regulation of immune responses and cancer progression. ATF3 is an important regulator of immune responses and cancer progression. In inactive immune cells, including macrophages, $\mathrm{NK}$ cells and $\mathrm{CD}^{+}, \mathrm{ATF} 3$ expression is maintained at low levels. Following activation of these cells by various signalling pathways including those initiated by TLRs, cytokines and antigen presentation, ATF3 is rapidly induced where it then binds its target promoters to regulate transcription. NF- $\kappa \mathrm{B}$ and AP-1 are transcription factors, well known for their ability to promote transcription of inflammatory cytokines and chemokines. ATF3 appears to directly antagonise NF- $\mathrm{KB}$ and AP-1 driven promoters, resulting in decreased expression of distinct subsets of cytokines and chemokines. Overall, ATF3 is therefore able to limit the intensity of the inflammatory response to infection and allergy, and ultimately prevent pathological conditions associated with uncontrolled output of inflammatory mediators. Controversially, ATF3 has also been suggested to plays roles as both a tumour suppressor and oncogene. Although the mechanisms that regulate ATF3 induction in cancer cells are largely unclear, it is possible that ATF3 could prevent tumour growth by repressing transcription of cell cycle genes (such as cyclin D1 and Id1) and cell survival genes (such as IRS2). Conversely, induction of metastatic mediators FN-1, TWIST-1 and Slug, or suppression of GADD153, a known proapoptotic gene, may implicate ATF3 as an oncogene. 


\begin{tabular}{|c|c|c|c|c|c|c|c|c|c|c|c|}
\hline & 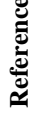 & $\bar{\Xi}$ & $\overline{\mathbb{d}}$ & $\overleftarrow{\Xi}$ & ¿্d & $\bar{\Xi}$ & 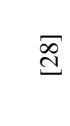 & $\stackrel{\bar{o}}{\dot{\alpha}}$ & $\bar{\Xi}$ & $\bar{I}$ & $\underset{\tilde{m}}{\tilde{n}}$ \\
\hline & 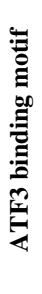 & 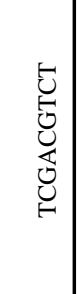 & 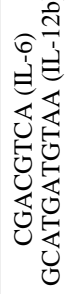 & ' & 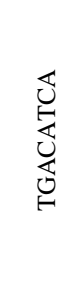 & ' & & & 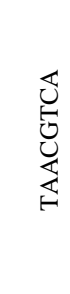 & & 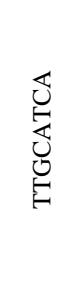 \\
\hline & 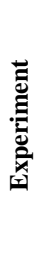 & 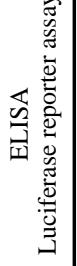 & 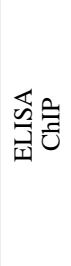 & 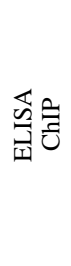 & 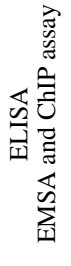 & 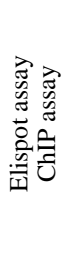 & 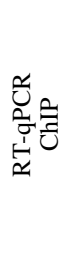 & 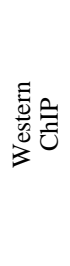 & 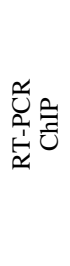 & छे & 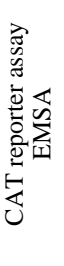 \\
\hline & 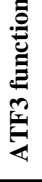 & 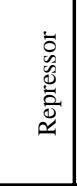 & 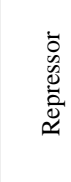 & 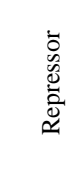 & 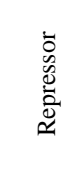 & 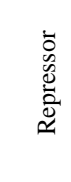 & 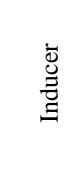 & 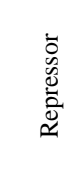 & 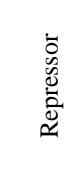 & 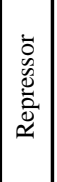 & 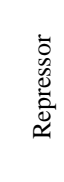 \\
\hline 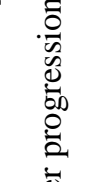 & 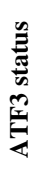 & 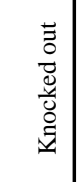 & 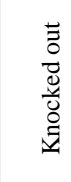 & 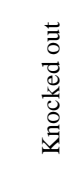 & 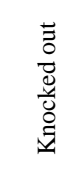 & 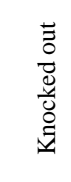 & 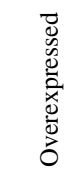 & 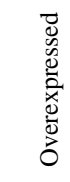 & 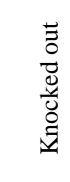 & 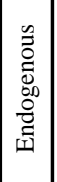 & 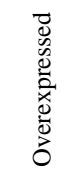 \\
\hline 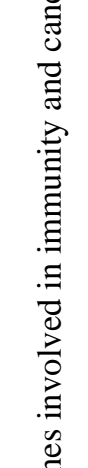 & & 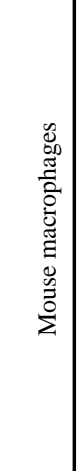 & 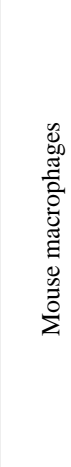 & 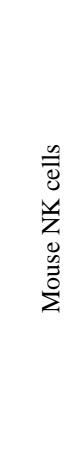 & 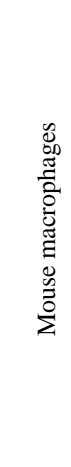 & 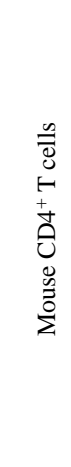 & 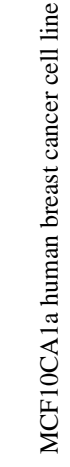 & 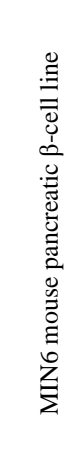 & 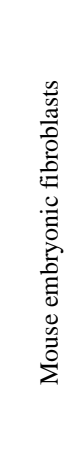 & 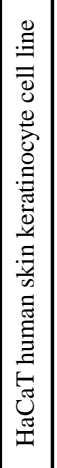 & 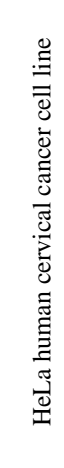 \\
\hline 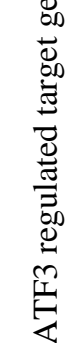 & 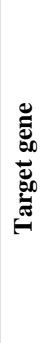 & 亮 & 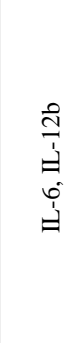 & 产 & 壱 & $\begin{array}{l}\stackrel{m}{H} \\
= \\
\stackrel{H}{=} \\
\stackrel{+}{=}\end{array}$ & 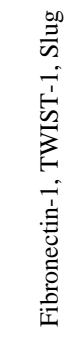 & $\begin{array}{l}\tilde{N} \\
\cong\end{array}$ & $\begin{array}{l}\overline{0} \\
\bar{g} \\
\overline{0}\end{array}$ & $\Xi$ & $\begin{array}{l}\tilde{n} \\
\hat{0} \\
\text { d. }\end{array}$ \\
\hline
\end{tabular}

